\title{
Preparation and Improved Physical Characteristics of Propylene Oxide Rubber Composites
}

\author{
Natalia N. Petrova ${ }^{1, *}$, Viktoriya V. Portnyagina ${ }^{2}$, Vasilii V. Mukhin ${ }^{1}$, Ee Le Shim ${ }^{3}$ and \\ Jin-Ho Cho ${ }^{4, *}$ \\ 1 Department of Chemistry, North-Eastern Federal University, Yakutsk 677000, Russia; mvvnj@yandex.ru \\ 2 Mining Institute, North-Eastern Federal University, Yakutsk 677000, Russia; vick_i@mail.ru \\ 3 School of Mechanical \& Automotive Engineering, Halla University, Wonju 220-712, Korea; \\ elshim@halla.ac.kr \\ 4 Department of Energy Science and Technology, Myongji University, Yongin 449-728, Korea \\ * Correspondence: pnn2002@mail.ru (N.N.P.); jinhcho@mju.ac.kr (J.-H.C.); \\ Tel.: +82-31-330-6237 (N.N.P. \& J.-H.C.)
}

Received: 9 August 2018; Accepted: 16 August 2018; Published: 27 August 2018

\begin{abstract}
Sealing rubbers employed in cold climates such as the Siberian Arctic must be able to withstand temperatures as low as $-50{ }^{\circ} \mathrm{C}$ while still exhibiting specific relaxation, strength, tribological characteristics, and a resistance to aggressive media. Previous investigations of propylene oxide rubber $\left(\mathrm{SKPO}, \mathrm{T}_{\mathrm{g}}=-73^{\circ} \mathrm{C}\right.$ ) modified with polytetrafluoroethylene (PTFE) have revealed that, while the rubber composite materials exhibit double the wear resistance compared to unmodified polypropylene oxide rubber, they have poor frost resistance. In the present study, we developed materials based on SKPO and ultrafine PTFE (UPTFE), which can be characterized by its smaller particle size, low molecular weight, high tribo-technical characteristics, and resistance to aggressive media. The properties of the rubber composites were evaluated using the standard methods. The structures of the materials were investigated by electron microscopy and XRD analysis. It was shown that the materials have excellent wear resistance, resistance to aggressive media, compression set, and low-temperature resistance. The addition of UPTFE is preferable to the addition of PTFE because the desired positive effects can be attained with only $0.5-1$ parts per hundred parts of rubber (phr) UPTFE while 20 phr PTFE would be necessary.
\end{abstract}

Keywords: propylene oxide rubber; ultrafine polytetrafluoroethylene; composite materials; frost resistance; wear resistance; hydrocarbon resistance

\section{Introduction}

Sealing rubbers must have high strength, high relaxation characteristics, excellent resistance to hydrocarbons, and good tribological characteristics [1,2] given that they are used in control machinery, feed machinery, power machinery, and other machinery systems that are exposed to pressure oscillations, pulse loads, liquid-hydrocarbon environments, and severe climates. In particular, the sealing rubbers employed in the Siberian arctic must be frost-resistant to very low temperatures $\left(<-55^{\circ} \mathrm{C}\right)$ despite rubber materials generally becoming fragile once the ambient temperature drops to their glass transition temperature $\left(\mathrm{T}_{\mathrm{g}}\right)$. The $\mathrm{T}_{\mathrm{g}}$ of most commercial rubbers is above $-50{ }^{\circ} \mathrm{C}$. For this reason, ordinary rubbers are not used in artic regions. Currently, butadiene nitrile rubber with a low acrylonitrile content is used because its $\mathrm{T}_{\mathrm{g}}$ is about $-50{ }^{\circ} \mathrm{C}[3,4]$. However, this rubber can still only offer limited resistance to hydrocarbon media and is easily damaged under actual arctic operating conditions because prolonged exposure to extremely low temperatures (down to $-55^{\circ} \mathrm{C}$ ) as well as high annual $\left(100^{\circ} \mathrm{C}\right)$ and daily $\left(25-30^{\circ} \mathrm{C}\right)$ temperature differences in the Siberian region 
have a significant impact on the reliable operation of machinery [1,2,5]. Faced with such conditions, the operating efficiency of the machinery is highly dependent on the sealing parts. For example, in the Republic of Sakha (Yakutia), up to 30\% of machinery failure cases in the fields of road transport, mining equipment, and pipelines are a result of the destruction or elasticity loss of rubber sealing parts [1]. In this respect, research to determine the most efficient modifiers and the development of new rational compositions of rubbers with a high level of frost, oil, and wear resistance is crucial. More specifically, the creation of new elastomeric sealing materials exhibiting high performance under severe Siberian arctic conditions is vital for industries engaged in the development of mineral resources such as oil and gas as well as the related processing activities.

Propylene oxide rubber (SKPO, specific grade, TU 2294-067-16810126-99), which is a copolymer of propylene oxide and $2.5 \%$ allyl glycidyl ether, was commercialized in 2002 by the JSC Sterlitamak Petrochemical Plant. It was developed specifically for cold climates with SKPO having an extremely low $\mathrm{T}_{\mathrm{g}}\left(-74^{\circ} \mathrm{C}\right)[6]$. Several investigations in which SKPO was modified with 20 parts per hundred parts of rubber (phr) [7] of PTFE revealed that the rubber composite material exhibits a 15\% greater oil resistance and double the wear resistance compared to unmodified polypropylene oxide rubber but exhibits poor frost resistance [8-10]. Consequently, an SKPO/PTFE composite was not sufficiently resilient to use in the severe Siberian environment.

UPTFE (brand name: "Forum") is a PTFE with a molecular weight that is relatively lower than that of ordinary PTFE [11-20]. UPTFE has unique thermal and aggressive media resistance, chemical resistance, a low coefficient of friction, and can withstand temperatures of $-169^{\circ} \mathrm{C}$ to $270{ }^{\circ} \mathrm{C}[13,14]$. UPTFE particles are spherical with a diameter of $0.5 \mu \mathrm{m}$ to $4.5 \mu \mathrm{m}$ while the diameter of ordinary PTFE particles is $1.8 \mu \mathrm{m}$ to $10 \mu \mathrm{m}$ [12]. UPTFE is less heat resistant and more soluble in polar solvents such as acetone and alcohol than ordinary PTFE. Therefore, UPTFE exhibits enhanced adhesion to metal surfaces. UPTFE is used as an additive in oils because the UPTFE particles become firmly bonded to metal surfaces and fill any surface roughness with a dense film. Thus, this reduces the friction coefficient between the metal surfaces and protecting those surfaces from wear and corrosion [11]. A similar surface action mechanism would most likely occur if UPTFE were to be added to SKPO-based rubber composites because the smaller size of the UPTFE particles in the rubber composites should result in superior properties. In the present study, propylene oxide rubber composites with UPTFE ("Forum" brand, TU 2229-004-02698192-2002) [11-14] was investigated to achieve oil, wear, and frost resistance as well as enhanced mechanical properties in our ongoing effort to devise a material that can be applied even in arctic conditions.

\section{Materials and Methods}

SKPO-UPTFE (JSC "Sterlitamak Petrochemical Plant", Sterlitamak, Russia) rubber composites [6] were produced using the same process as that used to produce standard SKPO rubber composites. As shown in Table 1, the SKPO-UPTFE rubber composites contain several ingredients such as a dispersant, sulfur, vulcanization accelerator, activator, filler, and an antioxidant. SKPO-UPTFE rubber composites were blended in a Plasticorder (Brabender PL-2200-3, Duisburg, Germany) at $35^{\circ} \mathrm{C}$ to $70{ }^{\circ} \mathrm{C}$ for $20 \mathrm{~min}$ while maintaining the phr concentration of the other constituents. First, SKPO was placed in the mixer together with the dispersant, zinc oxide, and the curing group. At the 9-min mark, UPTFE was added. Then, carbon black, plasticizer, and sulfur were added at $17 \mathrm{~min}$ shortly before the end of blending. After $24 \mathrm{~h}$, the SKPO-UPTFE rubber composite was cured at $150{ }^{\circ} \mathrm{C}$ for $30 \mathrm{~min}$ in a hydraulic press.

The main technical characteristics of the resulting SKPO-UPTFE rubber composites were evaluated according to Russian standard methods (GOST 270-84, GOST 9.029-74, GOST 408-78, GOST 9.030-74 [21-24]). The wear resistance of the SKPO-UPTFE rubber composites was evaluated by the abrasion resistance determination method using an AR-40 device [25]. The structural characteristics of the SKPO-UPTFE rubber composites were investigated by using a scanning electron microscope (JEOL, JSM-6480LV, Tokyo, Japan) equipped with an EDS detector (Oxford, X-max20, High Wycombe, 
UK) as well as an X-ray powder diffractometer (Thermo Fisher Scientific, ARL X'TRA, Écublens, Switzerland,) with copper as the anode. The scan angle ranged from $3^{\circ}$ to $60^{\circ}$ while the step angle was $0.04^{\circ}$. The degree of crystallinity was determined to be the Thermo-Fisher crystallinity. The frost resistance of the rubber composites was tested according to the GOST 408-78 standard [23] where the frost resistance coefficient is the ratio of the elastic modulus at room temperature at a particular temperature.

\section{Results and Discussion}

Table 1 lists the compositions of standard SKPO rubber, SKPO-PTFE rubber composite, and SKPO-UPTFE rubber composite.

Table 1. Chemical Composition of SKPO rubbers (phr).

\begin{tabular}{cccc}
\hline Ingredients & SKPO & SKPO + 20 PTFE & SKPO + UPTFE \\
\hline SKPO & 100 & 100 & 100 \\
Stearic acid & 1.0 & 1.0 & 1.0 \\
Zinc oxide & 5.0 & 3.0 & 3.0 \\
2-mercapto-benzothiazole & - & 2.0 & 2.0 \\
Dibenzothiazyl disulfide & 1.5 & - & - \\
Thiuram disulfide & 1.0 & 2.0 & 2.0 \\
Phenyl- $\beta$ naphthylamine & 2.0 & - & - \\
Carbon black P-803 & 60.0 & 60.0 & 60.0 \\
Dibutoxyethyl adipate & 10.0 & - & - \\
Sulfur & 1.5 & 1.5 & 1.5 \\
PTFE & - & 20 & - \\
UPTFE & 0 & - & $0.5,1,3,5,10$ \\
\hline
\end{tabular}

The physical and mechanical properties of blended SKPO-UPTFE rubber composites were evaluated and are summarized in Table 2.

Table 2. Physical and Mechanical Properties of SKPO rubbers.

\begin{tabular}{ccccccccc}
\hline Properties & SKPO & SKPO + 20 PTFE & $\mathbf{1}$ & $\mathbf{2}$ & $\mathbf{3}$ & $\mathbf{4}$ & $\mathbf{5}$ & $\mathbf{6}$ \\
\hline$f_{P}(\mathrm{MPa})$ & 7.5 & 8.5 & 7.4 & 7.4 & 7.9 & 7.9 & 7.4 & 7.9 \\
$\varepsilon_{\mathrm{p}}(\%)$ & 192 & 180 & 240 & 268 & 268 & 232 & 230 & 228 \\
$f_{100}(\mathrm{MPa})$ & 4.9 & 5.8 & 3.3 & 3.2 & 3.2 & 3.2 & 3.6 & 3.7 \\
$K_{V}$ & 0.88 & 0.47 & 0.99 & 0.97 & 0.98 & 0.96 & 0.95 & 0.90 \\
$C(\%)$ & 58.3 & 53.5 & 54.0 & 52.0 & 52.0 & 62.0 & 63.0 & 68.0 \\
$\Delta V\left(\mathrm{~cm}^{3}\right)$ & 0.17 & 0.11 & 0.11 & 0.10 & 0.12 & 0.13 & 0.14 & 0.15 \\
$\Delta Q(\%)$ & 22.0 & 18.0 & 17.0 & 17.2 & 18.3 & 19.4 & 21.5 & 22.2 \\
\hline
\end{tabular}

1: SKPO + 0.5 phr UPTFE, 2: SKPO + 1 phr UPTFE, 3: SKPO + 3.0 phr UPTFE, 4: SKPO + 5.0 phr UPTFE, 5: SKPO + $10.0 \mathrm{phr}$ UPTFE, $6:$ SKPO $+15.0 \mathrm{phr}$ UPTFE, $f_{P}$ : tensile strength, $\varepsilon_{\mathrm{p}}$ : elongation at break, $f_{100}$ : tensile stress at $100 \%$ elongation, $K_{V}$ : frost resistance coefficient with tension at $-50{ }^{\circ} \mathrm{C}, \mathrm{C}$ : compression set at $100{ }^{\circ} \mathrm{C}$ and $72 \mathrm{~h}, \Delta V$ : volumetric wear, $\Delta \mathrm{Q}$ : degree of swelling at $70^{\circ} \mathrm{C}$ and $72 \mathrm{~h}$ in oil.

UPTFE is a more rigid polymer with a higher modulus than SKPO. Larger amounts of UPTFE lead to a reduction in elasticity due to a decrease in the flexibility and the mobility of the propylene oxide rubber. These factors decrease the elongation at break. A significant amount ( $20 \mathrm{phr}$ ) of PTFE (rigid polymer) in SKPO inhibits the development of high-elastic deformation at both room and low temperatures, which leads to the sharp decrease in the frost-resistance coefficient $\left(\mathrm{K}_{\mathrm{V}}\right)$. Because the particle size of UPTFE is much smaller than that of PTFE, the SKPO-UPTFE rubber composite exhibits a frost resistance of $>0.90$. Small particles of UPTFE with a low coefficient of friction can also be regarded as being a dry lubricant, which facilitates the slipping of the SKPO macromolecules and restructuring under deformation at low temperatures. The $\mathrm{T}_{\mathrm{g}}$ value of standard SKPO rubber was 
$64.6^{\circ} \mathrm{C}$ while the $\mathrm{T}_{\mathrm{g}}$ values of all the SKPO-UPTFE rubber composites were no higher than that of the standard SKPO rubber.

In general, SKPO-UPTFE rubber composites exhibit significant improvements in wear and oil resistance, relaxation properties (compression set), and frost resistance at low UPTFE filler dosages $(<5 \mathrm{phr})$. The best SKPO-UPTFE rubber composite was obtained with $1 \mathrm{phr}$ UPTFE to the SKPO, which is shown in Table 2. With this composition, the volumetric wear, degree of swelling, and compression set are reduced by $41 \%, 22 \%$, and $11 \%$, respectively, while the frost resistance coefficient at $-50{ }^{\circ} \mathrm{C}$ is increased by $12 \%$ relative to that of standard SKPO rubber. As shown in Table 2, the addition of small amounts (0.5-1 phr UPTFE) relative to a large amount ( $20 \mathrm{phr}$ ) of PTFE was enough to improve the physical and mechanical properties $[9,10]$. The enhanced properties cannot be explained by the low friction coefficient of the added UPTFE alone and require further detailed study.

SEM images of the standard SKPO rubber, SKPO-PTFE rubber composite, and SKPO-UPTFE rubber composites were investigated to evaluate the structural changes. The external surface as well as the interior of the rubber composites (obtained by dipping them in liquid nitrogen and then crushing them) were investigated. The ordinary PTFE particles were found to be significantly larger than the UPTFE particles, which is shown in Figure 1a,c. Both the PTFE and UPTFE have similar polymeric structures before and after their addition to SKPO rubber, which is shown in Figure 1b,d.
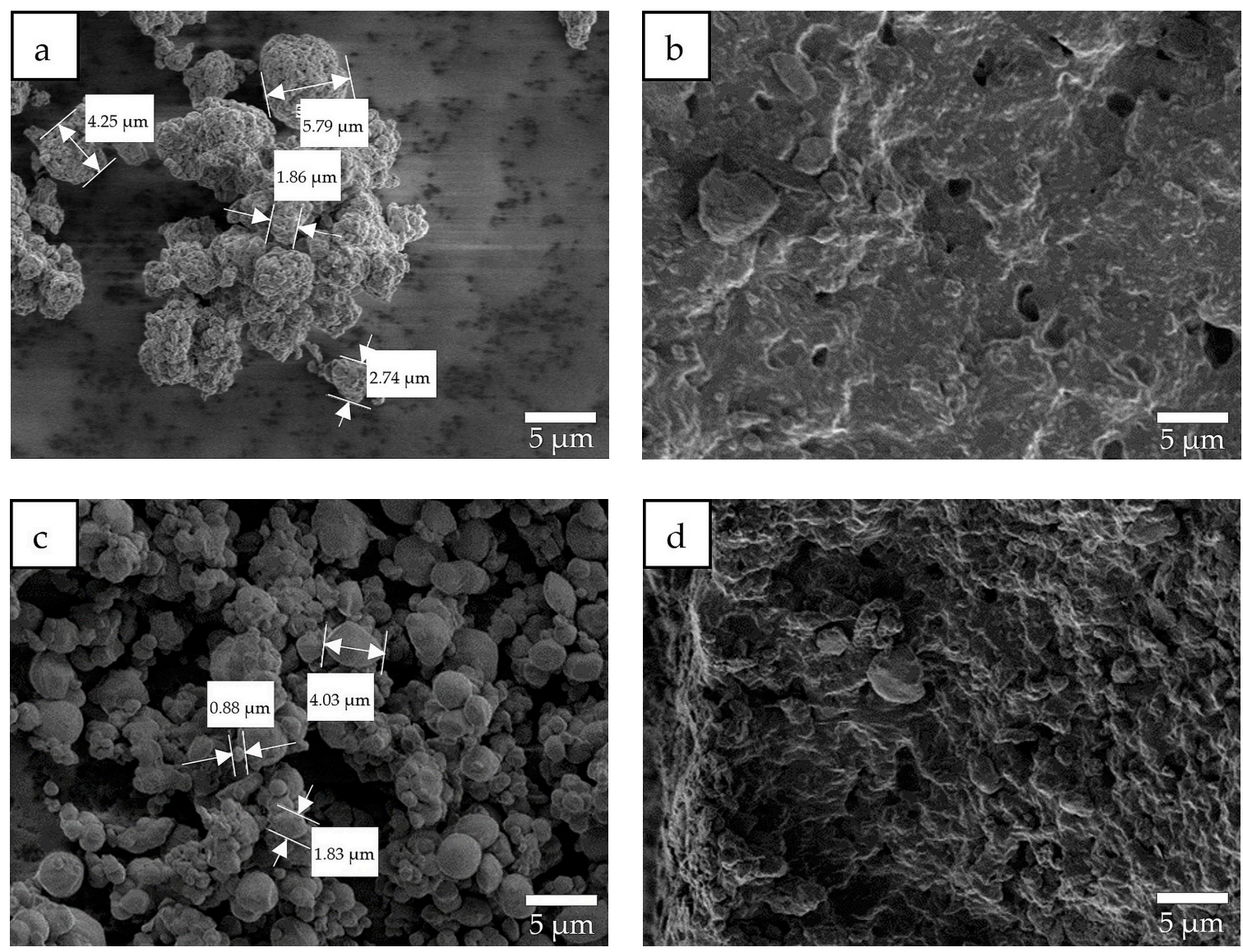

Figure 1. SEM images (× 3000): (a) PTFE, (b) SKPO + 10 phr PTFE, (c) UPTFE, and (d) SKPO + 10 phr UPTFE.

EDS data for the SKPO-UPTFE rubber composite containing 1 phr UPTFE reveals a uniform distribution of UPTFE particles in the SKPO, which is shown in Figure 2a,b. The particle size of the local UPTFE aggregates is less than $10 \mu \mathrm{m}$, which is shown in Figure 2a. Because of the agglomeration, the particle size of UPTFE increases to $40 \mu \mathrm{m}$ at $15 \mathrm{phr}$ UPTFE, which is shown in Figure 2c. UPTFE particles are localized into agglomerates $(>10 \mu \mathrm{m})$, which indicates weak interfacial interactions between SKPO 
and UPTFE. This is shown in Figure 2c,d. SEM images of the SKPO-UPTFE rubber composites are shown in Figure 3a,b, which can be seen to correspond to the EDS data shown in Figure 2.
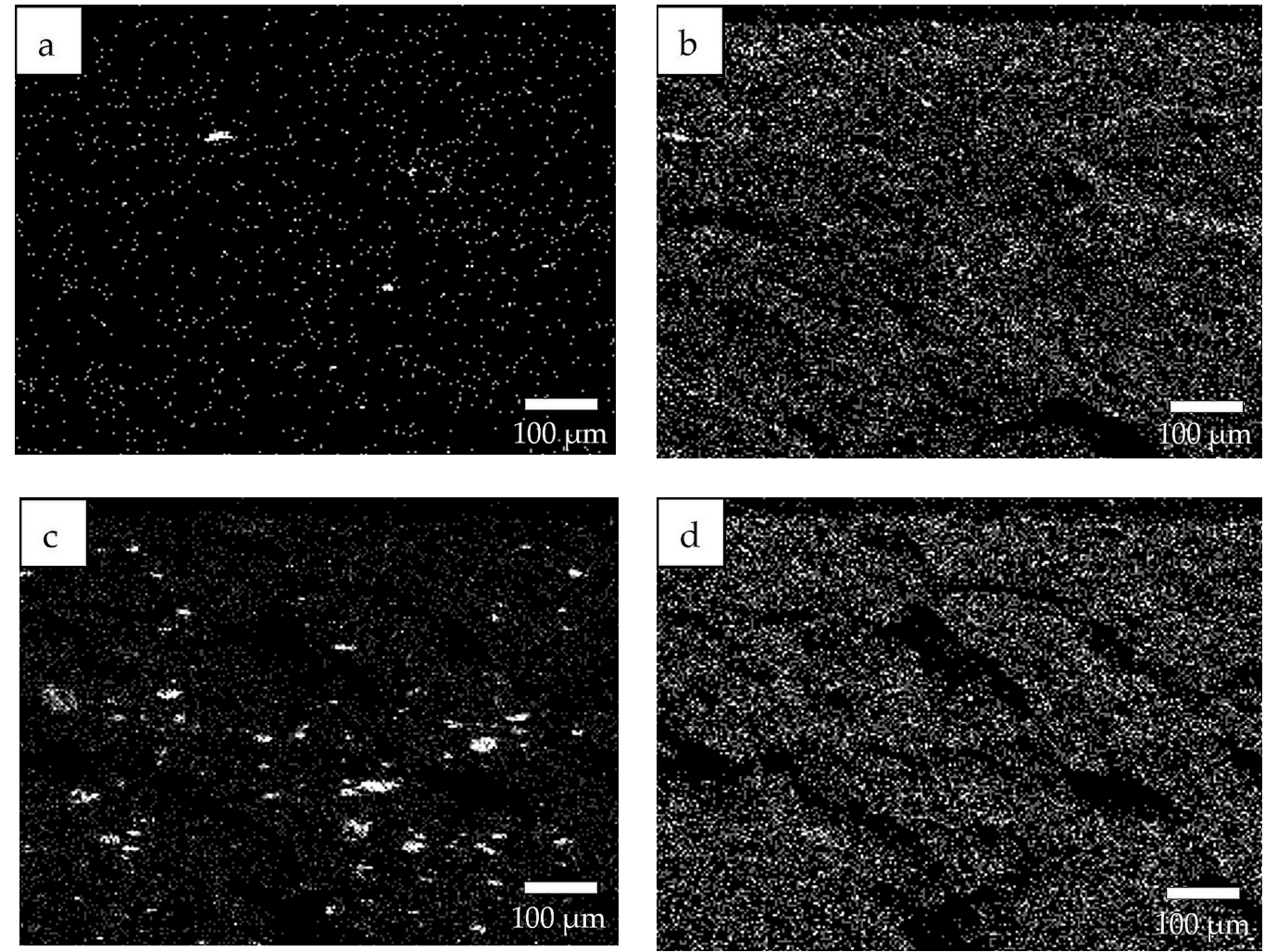

Figure 2. EDS data for the SKPO +UPTFE rubber composites ( $\times 50)$ : (a) EDS of fluorine, 1 phr UPTFE, (b) EDS of oxygen, 1 phr UPTFE, (c) EDS of fluorine, 15 phr UPTFE, and (d) EDS of oxygen, 15 phr UPTFE.
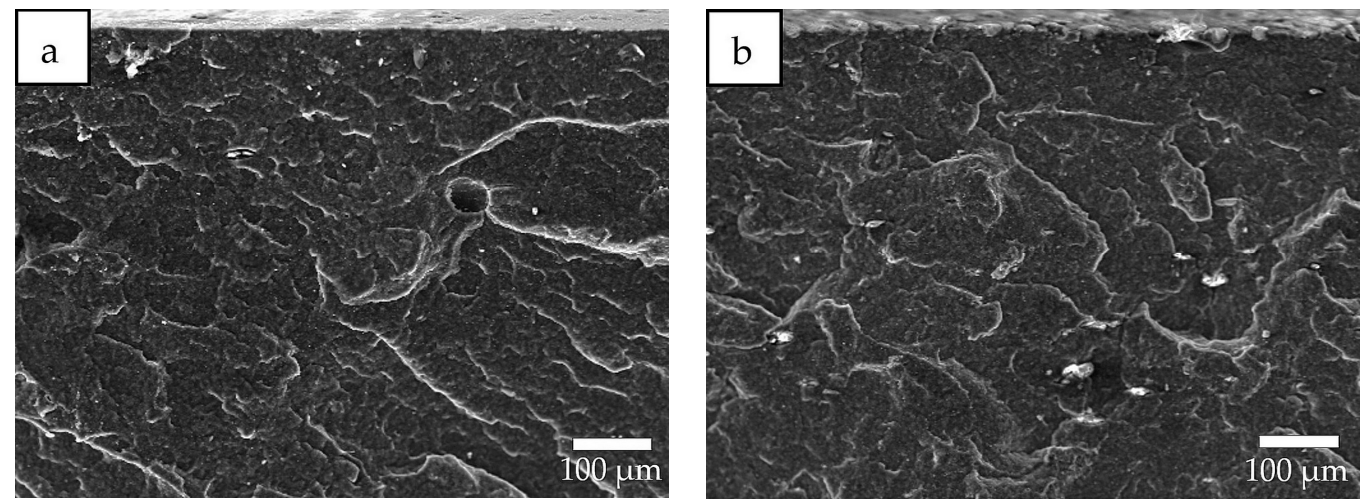

Figure 3. SEM images of SKPO + UPTFE rubber composites: (a) SEM, 1 phr UPTFE, and (b) SEM, 15 phr UPTFE.

The EDS spectra of an SKPO rubber composite containing 1 phr UPTFE reveals that the amount of fluorine on the surface of a rubber composite is greater than that inside the rubber composite, which is shown in Figure 4a,b.

This means that the UPTFE particles tend to concentrate on the surface of the rubber composite. The surface tension $(\sigma)$ of PTFE is $19 \mathrm{mN} / \mathrm{m}$ while that of SKPO is $32 \mathrm{mN} / \mathrm{m}$ [26]. This data is 
consistent with the observations described above, which show that the PTFE and its lower surface tension, migrates to the surface of the rubber composite.
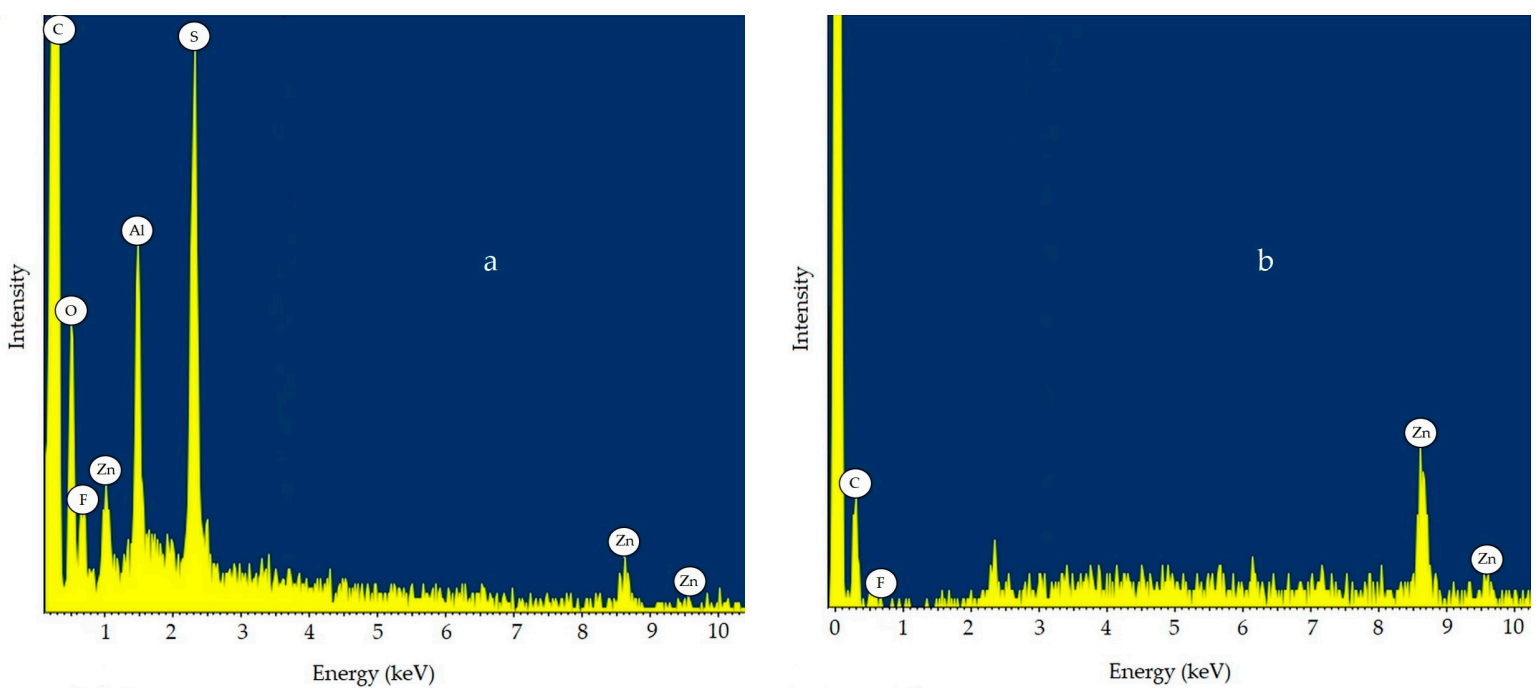

Figure 4. EDS spectrum for SKPO + 1 phr UPTFE rubber composite at: (a) surface of rubber composite and $(\mathbf{b})$ interior of rubber composite.

The surfaces of the SKPO and SKPO-UPTFE rubber composite were investigated by XRD analysis, which is shown in Figure 5. The SKPO containing 10 phr UPTFE exhibits a characteristic peak at a $2 \theta$ value of $18^{\circ}$, which originated from the UPTFE. On the other hand, there is no peak at $2 \theta=18^{\circ}$ in the case of the SKPO rubber composite containing 1 phr UPTFE. Therefore, to analyze the interior of the rubber composite containing SKPO and 1 phr UPTFE, another method such as X-ray photoelectron spectroscopy [27] would be required.

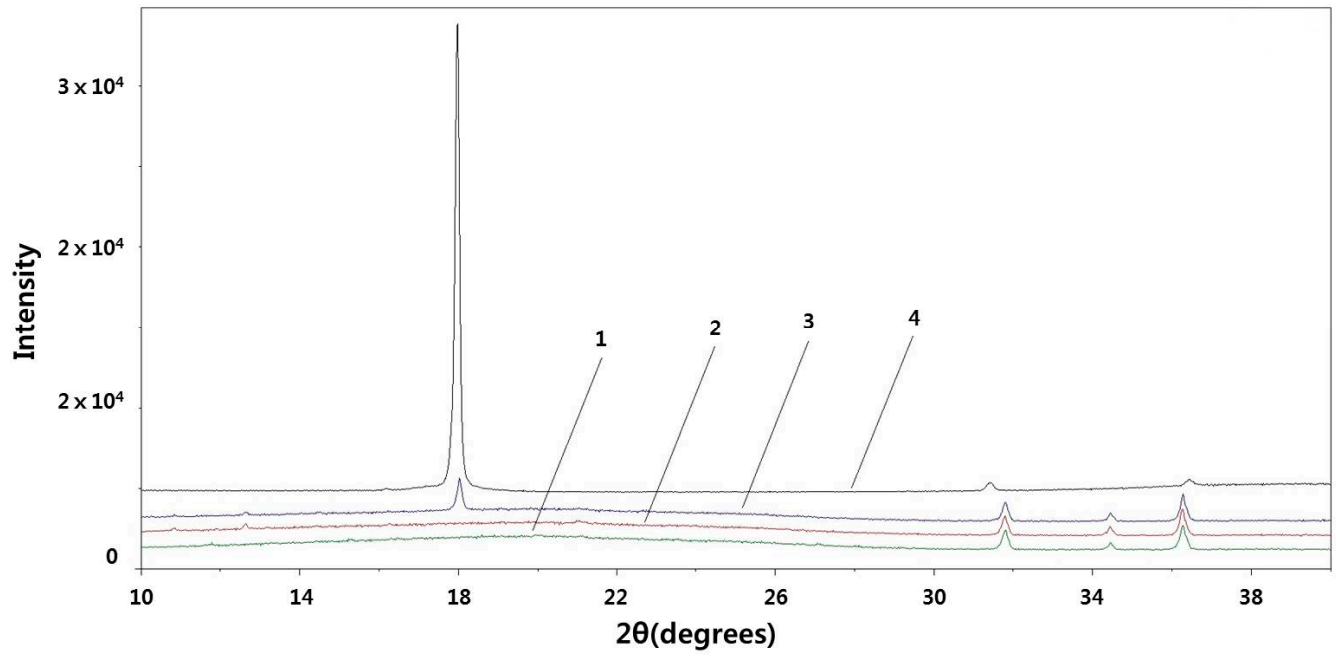

Figure 5. XRD patterns of: (1) initial SKPO rubber, (2) SKPO + 1 phr UPTFE rubber composite, (3) SKPO + 10 phr UPTFE rubber composite, and (4) UPTFE.

The XRD patterns for the surface and interior of the SKPO rubber composite containing 1 phr UPTFE are shown in Figure 6. The XRD method fails to detect 1-phr UPTFE, which is shown in Figure 6. 


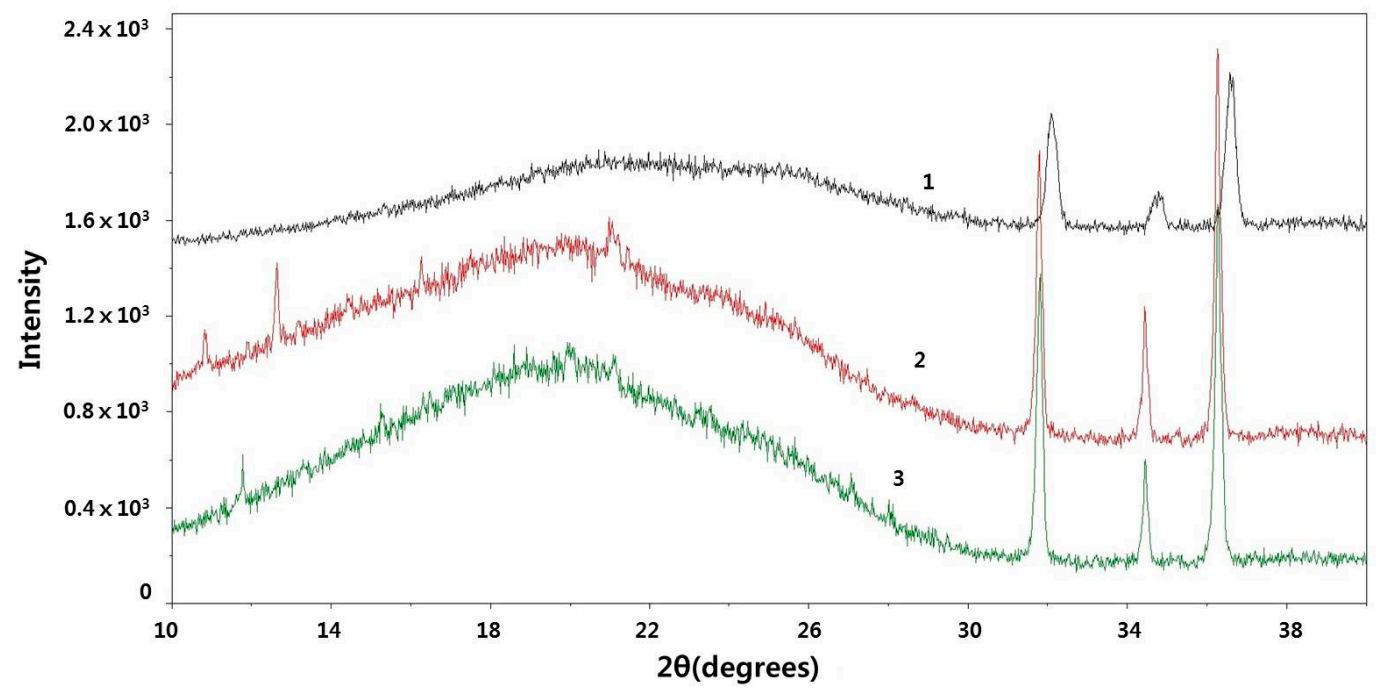

Figure 6. XRD pattern of SKPO + 1 phr UPTFE rubber composite: (1) interior of rubber composite, (2) surface, and (3) standard SKPO rubber.

New peaks at $2 \theta$ values of $13^{\circ}$ and $11^{\circ}$ are observed on the surface of this rubber composite. These peaks are assumed to originate from the low-molecular-weight fraction of the UPTFE during the vulcanization of the rubber because the low-molecular-weight fraction has a lower melting point and higher mobility and, therefore, can be mobilized at a processing temperature of $150^{\circ} \mathrm{C}$ [12].

On the other hand, the three peaks at $2 \theta$ values of between $30^{\circ}$ and $38^{\circ}$ originate from $\mathrm{ZnO}$ (part of the curing system, 5 phr in the SKPO rubber).

\section{Conclusions}

An SKPO rubber composite containing 1 phr UPTFE has the same mechanical and wear resistance properties as that addressed in our previous study, which contained 20 phr PTFE $[9,10]$ but offers superior frost resistance. This significant reduction in the required amount of filler is a result of using smaller and, therefore, more uniformly distributed particles of UPTFE in the rubber matrix compared to that achieved with PTFE. Furthermore, weak interactions between the SKPO and UPTFE may be attributed to the difference in the physical and chemical properties such as the polarity, surface tension, and van der Waals forces between them. This leads to the UPTFE migrating towards the surfaces of the rubber composites. Since UPTFE has a low friction coefficient, the relatively high concentration of UPTFE on the surface minimizes the friction between the metal parts and can lead to the protection of the sealing materials during the operation of the machinery. Such rubbers would, therefore, be ideal for manufacturing rubber sealing materials intended for applications in extreme arctic conditions.

\section{Patents}

This rubber composite material has been patented in the Russian Federation and the United States $[28,29]$.

Author Contributions: N.N.P. conceived and designed the experiments. V.V.P. performed the experiments. N.N.P. and V.V.P. analyzed the data. E.L.S. contributed analysis tools. V.V.P., N.N.P., V.V.M. and J.-H.C. wrote and edited the paper.

Funding: This work was supported by the Ministry of Education and Science of the Russian Federation, State assignment no. 11.1557.2017/П4; The research in Korea was supported by the National Research Foundation of Korea (NRF 2017R1C1B5017892).

Conflicts of Interest: The authors declare no conflict of interest. 


\section{References}

1. Chersky, I.N.; Morov, V.A. Analysis and prediction of rubber and seals serviceability in arctic conditions. Kautsch. Gummi Kunstst. 1990, 43, 128-129.

2. Nau, B.S. The state of the art of rubber-seal technology. Rubber Chem. Technol. 1987, 60, 381-416. [CrossRef]

3. Papkov, V.N.; Yuryev, A.N. Butadiene nitrile rubbers. In Handbook of Rubber Technologist; Reznichenko, S.V., Morozov, Y.L., Eds.; Izdatelskii Tsentr “Tekhinform” MAI: Moscow, Russia, 2012; Volume 1, pp. 186-210. ISBN 978-5-89551-023-0.

4. Petrova, N.N.; Popova, A.F.; Fedotova, E.S. Investigation of the influence of low temperatures and hydrocarbon media on the properties of rubbers based on propylene oxide and butadiene nitrile rubbers. Kauchuk I Rezina 2002, 3, 6-10.

5. Bishop, A.; Bremner, C.; Laake, A.; Strobbia, C.; Parno, P.; Utskot, G. Petroleum potential of the arctic: Challenges and solutions. Oilfield Rev. 2011, 22, 36-49.

6. Govorova, O.A.; Vishnitsky, A.S.; Chubarova, G.V.; Morozov, Y.L. Development of weather-resistant rubbers with improved low-temperature and adhesive properties. Kauchuk I Rezina 1999, 2, 18-20.

7. Rodgers, B.; Waddell, W. The science of rubber compounding. In Science and Technology of Rubber, 3rd ed.; Mark, E.J., Erman, B., Eirich, F.R., Eds.; Elsevier Academic Press: Burlington, VT, USA, 2005; pp. 401-452. ISBN 0-12-464786-3.

8. Petrova, N.N. Principles of Oil and Frost Resistant Rubbers Creation and Their Implementation for Operation in Cold Climate Conditions. Ph.D. Thesis, Moscow State University of Fine Chemical Technologies, Moscow, Russia, 2006.

9. Petrova, N.N.; Portnyagina, V.V.; Biklibaeva, R.F. Wear Resistant Rubber Blend Based on Propylene Oxide Rubber. Russian Patent 2,294,346, 27 February 2007.

10. Petrova, N.N.; Portnyagina, V.V. Propylene rubbers based on propylene oxide rubber and PTFE compositions. Kauchuk I Rezina 2007, 4, 8-11.

11. Bouznik, V.M.; Fomin, V.M.; Alkhimov, A.P. Metal-Polymer Nanocomposites, 2nd ed.; SB RAS Publishing House: Novosibirsk, Russia, 2005; pp. 8-97. ISBN 5-7692-0735-3.

12. Bouznik, V.M.; Kuryavy, V.G. Morphology and structure of micron and nanosized powders of PTFE obtained by gas-phase method. Rus. J. Gen. Chem. 2008, LII, 131-139.

13. Bouznik, V.M.; Kirik, S.D.; Solovyov, L.A.; Tsvetnikov, A.K. A crystal structure of ultra-dispersed form of polytetrafluoroethylene based on X-ray powder diffraction data. Powder Diffr. 2004, 19, 135-141. [CrossRef]

14. Bouznik, V.M.; Vopilov, Y.E.; Dedov, S.A.; Ignatieva, L.N.; Murin, A.S.; Slobodyuk, A.B. Structure of ultrafine polytetrafluoroethylene powders obtained from industrial wastes via hydrothermal method. Chem. Sustain. Dev. 2010, 18, 33-39.

15. Kuryavy, V.G.; Tsvetnikov, A.K.; Bouznik, V.M. Peculiarities of the hierarchical and morphological structure of the UPTFE particles according data from transmission electron and atomic force microscopy. Perspekt. Mater. 2005, 3, 86-90.

16. Polonik, V.D.; Prokopchuk, N.R.; Shashok, Z.S. Swelling degree of the ultrafine polytetrafluoroethylene containing elastomers. In Chemical Technology and Biotechnology of New Materials and Products, Proceedings of IV Mendeleev D.I. International Conference of Russian Chemical Society Dedicated to Sarkisov P.D., Moscow, Russia, 23-25 October 2012; Dmitry Mendeleev University of Chemical Technology of Russia: Moscow, Russia, 2012; pp. 140-141.

17. Prorokova, N.P.; Vavilova, S.Y.; Bouznik, V.M.; Zavadsky, A.E. Modification of the polypropylene fibrous materials with ultrafine polytetrafluorethylene. Polym. Sci. Ser. A 2013, 55, 1333-1342. [CrossRef]

18. Vopilov, Y.E.; Nikitin, L.N. Separation of low-molecular-weight fractions of ultrafine polytetrafluoroethylene with supercritical carbon dioxide. Rus. J. Phys. Chem. B 2009, 3, 1074-1081. [CrossRef]

19. Morozov, A.V.; Petrova, N.N. Method of evaluating the coefficient of friction of frost-resistant sealing rubbers. J. Frict. Wear 2016, 37, 124-128. [CrossRef]

20. Stolyarova, O.O.; Muravyeva, T.I.; Morozov, A.V.; Zagorskiy, D.L.; Gainutdinov, R.V.; Petrova, N.N.; Portnyagina, V.V. Electron and probe microscopy investigation of the surface of elastomers modified with antifriction fillers. J. Surf. Investig. X-Ray Synchrotron Neutron Tech. 2016, 10, 925-932. [CrossRef]

21. GOST 270-84 State Standard. Rubber: Method of the Determination Elastic and Tensile Stress-Strain Properties. Available online: http:/ /vsegost.com/Catalog/21/21850.shtml (accessed on 24 January 2018). 
22. GOST 9.024-74 State Standard. Unified System of Corrosion and Aging Protection-Rubbers: Methods of Heat Aging Stability Determination. Available online: http://vsegost.com/Catalog/36/36404.shtml (accessed on 24 January 2018).

23. GOST 408-78 State Standard. Rubber: Methods of Measuring Low Temperature Resistance at Extension. Available online: http://vsegost.com/Catalog/24/24460.shtml (accessed on 24 January 2018).

24. GOST 9.030-74 State Standard. Unified System of Corrosion and Aging Protection-Vulcanized Rubbers: Method of Testing Resistance to Attack by Corrosive Media in Limp State. Available online: http:/ /vsegost. com/Catalog/35/3586.shtml (accessed on 24 January 2018).

25. GOST 23509-79 State Standard. Rubber: Method of Determining the Abrasion Resistance of the Sliding on Renewable Surface. Available online: http://vsegost.com/Catalog/80/8045.shtml (accessed on 24 January 2018).

26. Van Krevelen, D.W.; te Nijenhuis, K. Properties of Polymers, 4th ed.; Elsevier: Amsterdam, The Netherlands, 2009; pp. 229-244.

27. Martínez, L.; Román, E.; Nevshupa, R. X-Ray photoelectron spectroscopy for characterization of engineered elastomer surfaces. In Advanced Aspects of Spectroscopy; Farrukh, M.A., Ed.; InTech: Rijeka, Croatia, 2012; pp. 165-194. ISBN 978-953-51-0715-6.

28. Petrova, N.N.; Portnyagina, V.V. Wear Resistant Rubber Based on Propylene Oxide Rubber and Ultrafine polytetrafluoroethylene. Russian Patent 2,502,759, 27 December 2013.

29. Petrova, N.N.; Portnyagina, V.V. Wear-Resistant Rubber Based on Propylene Oxide Rubber and Ultrafine Polytetrafluoroethylene. U.S. Patent 8,841,370, 23 November 2014.

Sample Availability: Samples of the compounds are not available from the authors.

(C) 2018 by the authors. Licensee MDPI, Basel, Switzerland. This article is an open access article distributed under the terms and conditions of the Creative Commons Attribution (CC BY) license (http://creativecommons.org/licenses/by/4.0/). 